Proc. Estonian Acad. Sci. Geol., 2002, 51, 4, 199-214

\title{
An improved gravity anomaly grid and a geoid model for Estonia
}

\begin{abstract}
Artu Ellmann
Division of Geodesy, Royal Institute of Technology (KTH), SE-100 44 Stockholm, Sweden; ellmann@geomatics.kth.se

Received 4 March 2002, in revised form 22 April 2002

Abstract. A regular $1.5^{\prime} \times 3^{\prime}$ grid of free-air gravity anomalies over Estonia is computed. The study comprises the improved gravity data coverage in the Baltic Sea region during the past few years. The estimated precision of the predicted anomalies is $2.4 \mathrm{mGal}$ in Estonia. The gravity anomaly grid and the geopotential model EGM96 are utilized in the computation of the Estonian gravimetric geoid model EST-01 by the least squares modification of Stokes' formula. The model is fitted to a set of 26 high-precision GPS-levelling points, yielding an accuracy of $3.0 \mathrm{~cm}$ for the postfitting residuals, which indicates the suitability of EST-01 for many practical applications.
\end{abstract}

Key words: gravity anomaly, prediction, geopotential model, gravimetric geoid, Stokes' formula, least squares modification, GPS-levelling.

\section{INTRODUCTION}

The geoid as an equipotential surface of the Earth's gravity field coincides with the mean sea level over the oceans and extends hypothetically into the continental regions. Caused by irregularities in mass distributions inside the Earth, the geoidal heights undulate with respect to the geodetic reference ellipsoid. The geoid plays an essential role in the national geodetic infrastructure as the topographic heights and the depths of the seas are reckoned from it. Thus, many applications in geodesy, geophysics, oceanography, and engineering require physically defined heights related to the geoid. Traditionally, the spirit levelling has been applied to accurate height determination.

During the past two decades the increased need for refined geoid models has been driven by demands of the Global Positioning System (GPS) users. Nowadays they must transform the GPS-derived geodetic heights (reckoned from a reference ellipsoid) into traditional heights to make them compatible with the local vertical datum. At discrete points a traditional height could be obtained by algebraically subtracting the value of the geoidal height from the geodetic height. 
Consequently, for the conversion and combination of these fundamentally different height systems, the geoid model must be known to an accuracy comparable to the accuracy of GPS and traditional levelling, i.e. a few centimetres.

The geoid models are strongly dependent on gravity data entering into the solutions. Perfectness of any theoretical method is diminished or even meaningless with insufficient data quality and coverage. In the best cases the accurate to $1 \mathrm{~cm}$ (in relative sense for short baselines below $10 \mathrm{~km}$ ) geoid can be obtained with gravity data spaced around 2-3 km (see, e.g., Forsberg 2001).

In 1994, when only limited data were available, the gravimetric geoid of Estonia was computed by Vermeer (1994) at the Finnish Geodetic Institute. The geoid determination for the whole Nordic region, recently extended to the Baltic countries, has been carried out within the framework of the Nordic Geodetic Commission (NKG). The latest geoid model, which covers also Estonia, is NKG96 (Forsberg et al. 1997). In 1998 the Estonian part of the latter was supplemented with the national gravity network data and thereafter recomputed (Jürgenson 1999).

In the past few years, as a result of international cooperation, the coverage of gravity data has significantly improved in the Baltic Sea region. The treatment of data collected with different methods and equipment, during several decades by different nations and specifications, requires careful study before the geoid computation. This paper is focused on the gravity data available for the area of our principal interest, Estonia. The grid of free-air gravity anomalies is used for the determination of the new Estonian gravimetric geoid. The applied computational strategy for geoid estimation differs from earlier geoid solutions. As proposed by Sjöberg (1984), a method called least squares modification of Stokes' formula is used. Considering the wide spectra of possible practical applications, primarily associated with the use of the GPS-technology, an attempt is made towards the national fit of the geoid model with the Estonian highprecision GPS-levelling points.

\section{THE GRAVITY ANOMALY GRID}

\section{Gravity anomalies}

Gravity measurements are used in studying the shape, composition, and structure of the Earth. The gravity measured on the Earth's physical surface is not directly comparable with normal gravity which is related to the reference ellipsoid. Observations are reduced to gravity anomalies in such a way that the features under study stand out as correctly as possible. The measured gravity values can be represented in several ways (see, e.g., Heiskanen \& Moritz 1967). In this research concern is given to the free-air and Bouguer gravity anomalies. Gravity anomalies are mainly used for (1) determination of the geoid, (2) interpolation and geophysical extrapolation of gravity, (3) geological mapping and exploration for natural resources, and (4) investigation of the Earth's crust. A gravity anomaly (hereafter simply referred to as anomaly) has the physical dimension of acceleration and is commonly expressed in CGS unit milligal $\left(1 \mathrm{mGal}=10^{-5} \mathrm{~m} \mathrm{~s}^{-2}\right)$. 
Free-air anomaly, $\Delta g_{F}$, which in a modern context (proposed in Molodensky 1945 ) is referred to the ground level, is defined as the difference between the actual gravity measured on the ground $g_{P}$ and the normal gravity $\gamma_{Q}$ :

$$
\Delta g_{F}=g_{P}-\gamma_{Q},
$$

where $Q$ is related to the normal height $H$ (continued upwards from the reference ellipsoid) of the survey point. The normal gravity $\gamma_{Q}$ can be calculated by using the approximate vertical gradient $0.3086 \mathrm{mGal} / \mathrm{m}$ :

$$
\gamma_{Q}=\gamma_{0}-0.3086 H
$$

where $H$ is in metres. The latitude-dependent normal gravity $\gamma_{0}$ can be calculated by a series expansion, e.g. after Moritz (1992). The Bouguer anomaly is given by

$$
\Delta g_{B}=g_{P}-\gamma_{Q}-2 \pi G \rho H,
$$

where the Newton's gravity constant $G=6.672585 \times 10^{-11} \mathrm{~m}^{3} \mathrm{~kg}^{-1} \mathrm{~s}^{-2}$ and $\rho$ is the density of the Bouguer plate. Considering Eq. (2) and the topographic density $\rho$ set to $2.67 \mathrm{~g} \mathrm{~cm}^{-3}$, the Bouguer anomaly can be calculated via free-air anomaly and height:

$$
\Delta g_{B}=\Delta g_{F}-0.11187 H
$$

As one can see from Eqs. (1)-(4), anomalies also depend on topography. An error of $3 \mathrm{~m}$ in height corresponds to $1 \mathrm{mGal}$ in anomaly value. Therefore, one has to use a terrain model as accurate as possible since any error in heights will propagate to the anomalies. For the geoid computation the free-air anomalies are in use. On the other hand, Bouguer gravity anomalies display better the subsurface density variations and shallow features. The free-air anomaly is known to be more sensitive to the topography, so, if there are rough topographic masses in the computation area, the free-air anomalies will be rough and that is why the interpolation cannot always be successful. In order to achieve a better result for such an area, the interpolation could be done by means of the less topography dependent Bouguer anomaly.

\section{Target area}

Estonia lies on the eastern shore of the Baltic Sea, bordering Latvia and Russia. The total area of Estonia is approximately $45200 \mathrm{~km}^{2}$ (including inner waters and islands), the elevation extremes are $0 \mathrm{~m}$ at shoreline and $318 \mathrm{~m}$ in southeast Estonia.

For the current study the target area is defined as the area in which a grid of gravity anomalies and a gravimetric geoid model are calculated. Its geographical limits are from $57.5^{\circ}$ to $59.7^{\circ}$ northern latitude and from $21.8^{\circ}$ to $28.3^{\circ}$ eastern longitude (Fig. 1). In addition to the Estonian mainland and islands, the target 


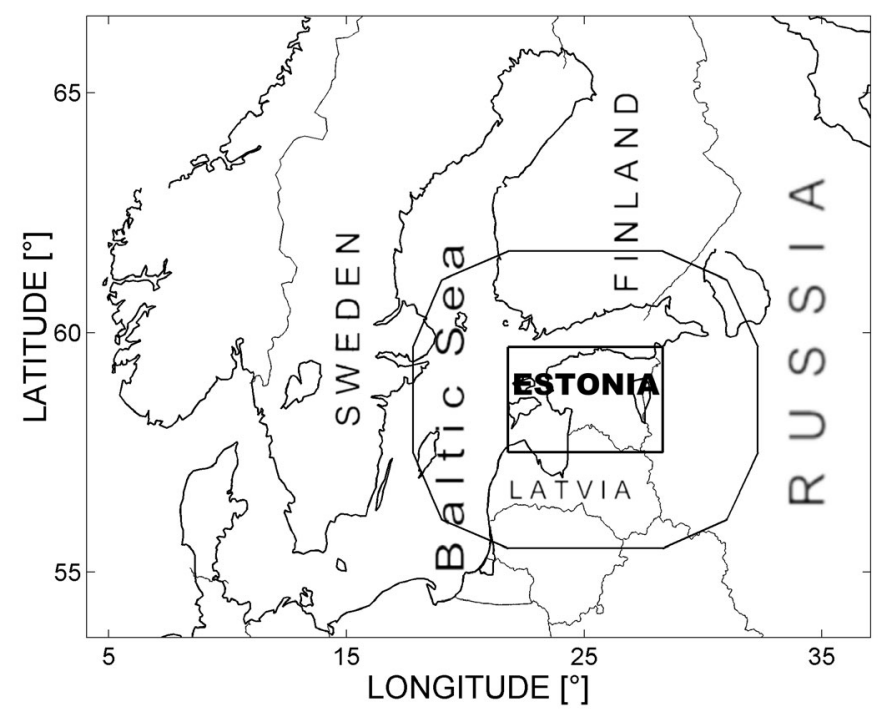

Fig. 1. Location of the target area. The ellipsoid-shaped polygon encloses the target area at a spherical distance of $2^{\circ}$ (approx. $220 \mathrm{~km}$ ) from its borders.

area (approx. $83500 \mathrm{~km}^{2}$ ) involves part of the Baltic Sea, the northern part of Latvia, and a small part of northwestern Russia. About $94 \%$ of the target area comprises sea and topography below $100 \mathrm{~m}$.

The Global Land One-kilometre Base Elevation model (GLOBE task team 1999) covers the whole target area. The accuracy of the GLOBE model was evaluated by using approx. 22500 height points of the Estonian 1:50 000 scale Base Map (Estonian Land Board 1996). From the test of GLOBE the systematic bias of $-2.6 \mathrm{~m}$ in Estonia and the root mean square error of differences $10 \mathrm{~m}$ were detected.

\section{Overview of the gravity surveys}

The gravity data used in the current research were obtained from the Danish National Survey and Cadastre, the authorized holder of the Nordic-Baltic gravity database. The data are related to the International Gravity Standardization Net 1971 (IGSN71), which means also that physical, geometrical and other values should be related to the Geodetic Reference System 1980 (GRS-80). The database is created and maintained within the frame of the activities of the NKG. The national contact persons deliver the data to the database, and the responsibility of the quality and corrections applied to the national datasets lies on them.

For each data-point the obtained information is as follows: point number, geographical coordinates (latitude and longitude), height (mainly related to sea level), and the free-air and Bouguer anomaly values. The geographical distribution of the gravity data-points in the target area is presented in Fig. 2. 


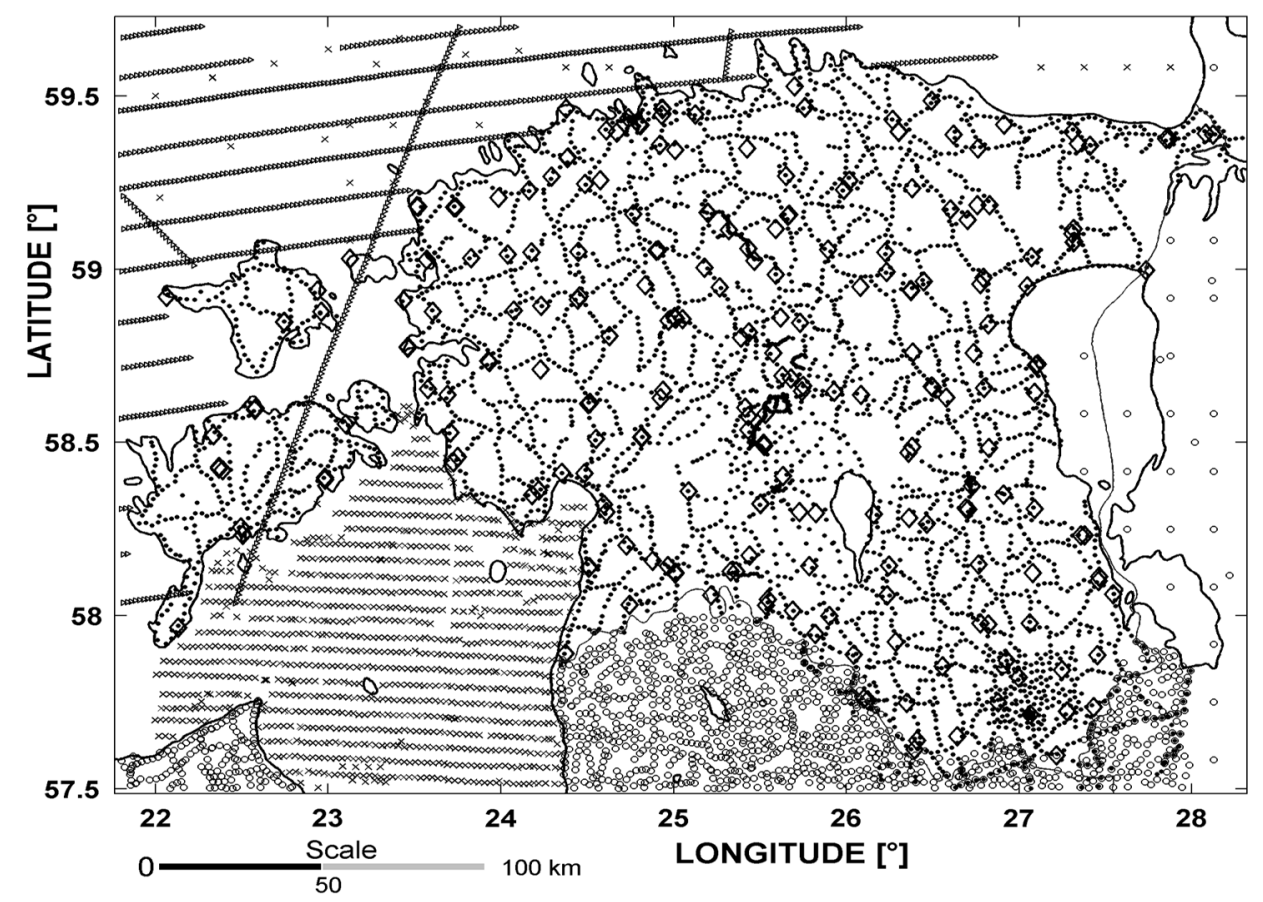

$\checkmark$ Estonian gravity network

- Estonian gravity survey

$\triangleright$ Baltic Sea 1999 aerogravity survey tracks

$\circ$ gravity points from Latvia and Russia

$\times$ sea gravity and the Gulf of Riga datasets

Fig. 2. Location of gravity data-points in the target area.

Several datasets from land and marine areas are available for the target area. The gravity coverage within the target area is more or less satisfactory, except for the eastern part, where only a little data are available from the offshore region and Russia. Aligned data-points in the northwestern part of the target area indicate the location of the aerogravity survey tracks. The number of gravity points within the target area is approximately 7600 , producing a density of one point per $11 \mathrm{~km}^{2}$. The quality of the gravity data affects directly the quality of subsequent geoid determination, and therefore any systematic or gross error should be removed. The extensive analysis of the data originating from different countries is summarized in Ellmann (2001). In this paper attention is focused on the following subjects: transformation of the national gravity values into the IGSN71 gravity system, divergence of time epochs, different approaches in the treatment of tidal effects, height and coordinate systems, influence of the Fennoscandian postglacial land uplift, etc. 
The Estonian gravity survey was performed by the Institute of Geology at the Estonian Academy of Sciences in 1949-58. According to Sildvee (1998), the gravity survey points were located mainly along the roads as traverses and loops with an average distance between stations of about $2 \mathrm{~km}$. The mean standard error of the gravity measurements is stated as $0.3 \mathrm{mGal}$. Heights of the survey points are related to the Kronstadt tide-gauge, the accuracy for height determination is stated as $0.5-1.5 \mathrm{~m}$. The periodic part of the tidal effects due to the attraction caused by the Sun and Moon was eliminated. Due to the lowness of topography the terrain corrections to the anomalies were not applied. The atmospheric effects on gravity measurements (i.e. as adopted in the definition of the GRS-80; see Moritz 1992) were not considered either. As emphasized in Sjöberg (1999), correcting for them would be dubious anyway, instead the influence of the atmospheric masses could be converted into a correction to the geoid model directly. The total number of Estonian gravity survey points exceeds 4000 , producing a density of approximately one survey point per $10 \mathrm{~km}^{2}$. Original results of the gravity survey in Estonia were related to the international Potsdam gravity system of 1930. After the absolute gravity measurements performed by the Finnish Geodetic Institute in 1995, the Estonian gravity network was readjusted. The difference of $-15.4 \mathrm{mGal}$ between the Potsdam and the absolute gravity systems in Estonia was detected. Thereafter, this correction was introduced to all gravity survey results. For the present research the coordinates of all Estonian gravity survey points were transformed into the new European terrestrial reference system ETRS-89.

Latvian gravity data are mainly digitized from the 1:200 000 scale paper maps. The accuracy of such data remains unknown (Kaminskis \& Forsberg 1997). While transforming the Latvian points from the Potsdam system into the IGSN71, the theoretical correction of $-14 \mathrm{mGal}$ was applied. It should be mentioned that the free-air anomalies for most Latvian gravity points are calculated via Bouguer anomalies complemented with the respective heights from an older version of GLOBE, thus, the resulting free-air anomalies could contain significant errors.

Baltic Sea 1999 aerogravity survey results are related to the point of the measurement (up to a couple of hundred metres above sea level), while only a small part of aerogravity survey tracks are crossing the low topographic masses. Over the marine areas the accuracy of the airborne free-air anomalies is estimated to be around $2 \mathrm{mGal}$ (Forsberg 2001). Sea gravity measurements and the Gulf of Riga dataset (the latter is digitized from 1:200000 scale paper maps) are related to the sea surface; the accuracy of these datasets remains unknown.

Unfortunately only a small number of gravity points are available from the Russian Federation. For filling such gaps the use of spherical coefficients from a global geopotential model (GGM) is a possibility. 


\section{Computation of the free-air anomalies from the geopotential model}

The Earth's gravitational potential could be expressed in terms of an infinite series of spherical harmonics outside the attracting masses of the Earth. While compiling such a GGM, the contribution from the artificial Earth satellites, gaining the long wavelength information of the Earth's gravity field, becomes especially important.

In the current investigation the Earth Geopotential Model EGM96 (Lemoine et al. 1997) is used. The EGM96 harmonic coefficients $\left(C_{n m}\right.$ and $\left.S_{n m}\right)$ are complete to degree and order 360. The model consists of a low degree (from 2 to 70) combination model (obtained from combining satellite tracking data, surface gravity data, and direct altimeter measurements) with a higher degree model. The EGM96 model represents a significant improvement over earlier models due to the release of new gravity data from formerly classified sources, as well as improved satellite tracking data. The free-air anomaly can be calculated from the geopotential model by the series

$$
\Delta g_{F}(r, \theta, \lambda)=\frac{G M}{r^{2}} \sum_{n=2}^{n_{\max }}\left(\frac{a}{r}\right)^{n}(n-1) \sum_{m=0}^{n}\left\{\bar{C}_{n m} \cos m \lambda+\bar{S}_{n m} \sin m \lambda\right\} \bar{P}_{n m}(\cos \theta),
$$

where $\bar{C}_{n m}, \bar{S}_{n m}$ are fully normalized spherical harmonic coefficients, of degree $n$ and order $m ; G M=398600.4415 \mathrm{~km}^{3} \mathrm{~s}^{-2}$ is an adopted gravity mass constant of the EGM96; $(r, \theta, \lambda)$ are geocentric radius, spherical colatitude, and longitude of the computational point, respectively; $a=6378136.3 \mathrm{~m}$ is the EGM96 equatorial radius (Lemoine et al. 1997), and $\bar{P}_{n m}$ is fully normalized associated Legendre function.

The free-air anomalies computed from the EGM96 were compared with the Estonian gravity survey results. The mean of all differences (control value subtracted from the one calculated from the EGM96) is $+0.57 \mathrm{mGal}$ and the root mean square error of differences is $9.2 \mathrm{mGal}$. Certainly, the accuracy of anomalies computed from the EGM96 is not comparable with the terrestrial measurements, but gives us a good idea of the range of the expected accuracy in a region where terrestrial gravity data are missing.

\section{Prediction of anomalies}

Many numerical procedures in Earth sciences require data on a regularly spaced grid of geographical coordinates. In contrast, most data are acquired at observation points located discretely or as traverses. For interpolation and extrapolation of the most representative values in a regular grid from randomly distributed observations, a special procedure, here called prediction, needs to be applied. Prediction of anomalies is a critical issue, because any error committed at this stage will directly propagate into the geoid solution.

Different methods for anomaly prediction are in use. For the current study Bjerhammar's deterministic method (Bjerhammar 1973, p. 324) of prediction is 
applied. Anomaly $\Delta \hat{g}_{j}$ at the point of prediction depends on the distance from the neighbouring points. In this method the following expression is used:

$$
\Delta \hat{g}_{j}=\frac{\sum_{i=1}^{n} \Delta g_{i} / s_{i j}^{v}}{\sum_{i=1}^{n} 1 / s_{i j}^{v}},
$$

where $v$ is the power of the prediction (it also provides the proper weights in the estimation process), $\Delta g_{i}$ is an observed anomaly, and $s_{i j}$ is the distance between the $i$ th observed point and the prediction point $j$.

A rectangular grid of $1.5^{\prime} \times 3^{\prime}$ (arc-minutes, approx. $2.7 \times 2.7 \mathrm{~km}^{2}$ ) blocks consists of 88 rows in north-south and 130 columns in east-west directions, respectively. A limited number of discrete data-points around the prediction point have to be used. In the case when at least 5 survey points were located inside the block, simply the mean of the observations was taken. For the ordinary prediction case the points located within a radius of $1^{\prime}(1.8 \mathrm{~km})$ were considered. When the number of points within this circle was less than 6 , the radius was increased by step $0.5^{\prime}$ until the number of points to be used for the prediction reached 6 . The radius for the prediction was increased only up to a maximum radius of $12^{\prime}$ $(22 \mathrm{~km})$. If the number of data-points within this area was less than 4, the gravity anomaly for the centre of the block was calculated from the EGM96 by Eq. (5) and the average of all values within a spherical distance of $12^{\prime}$ was taken. It should be mentioned that in the eastern part of the target area it was necessary to involve altogether 1100 gravity anomalies from the EGM96.

The best value of power $v$, as well as the estimation of predicted anomaly accuracy, could be obtained empirically by comparing the predicted values with known control points. For this purpose the 240 points of the Estonian gravity network were used. The network measurements were carried out more than 10 years after the gravity survey of 1949-58. Thus these two datasets can be considered as independent of each other. The values of the most recent adjustment (accuracy is stated to be $0.1 \mathrm{mGal}$ or better) were obtained from Sildvee \& Oja (2000).

Considering the low topography within the target area, the suitability of both types of anomalies for prediction was tested. When predicting free-air anomalies directly, the accuracy of prediction results is about $10 \%$ better compared to the case when free-air anomalies are predicted via combined use of Bouguer anomalies and GLOBE terrain heights. We may conclude that for such a lowland like Estonia it is better suited when free-air anomalies are predicted directly (avoids the deficiencies of the current GLOBE model).

Based on the resulting differences between control and predicted values, we also concluded that the power of prediction $v=2$ gave the best values. The precision of predicted free-air anomalies in Estonia is estimated as $2.4 \mathrm{mGal}$. However, such control points are lacking in the neighbouring countries and over the sea, and thus the accuracy of predicted anomalies remains unknown there. 


\section{Prediction results}

The predicted $1.5^{\prime} \times 3^{\prime}$ grid of free-air gravity anomalies is presented in Fig. 3 . In contrast to earlier maps of Estonian anomalies, e.g. reported in Sildvee (1998), the grid presented here is extended to offshore and neighbouring countries. Within the whole target area free-air anomalies vary from -66 to +32 mGal. The overall range of anomalies is thus almost $100 \mathrm{mGal}$. The predicted anomalies are relatively smooth (standard deviation of mean is $15.6 \mathrm{mGal}$ ), but it should also be noted that the eastern part of the target area is almost entirely calculated from the EGM96. Free-air anomalies within the target area are mainly negative (with a mean of $-8.6 \mathrm{mGal}$ ). Nevertheless, it can be noticed that the zone of positive anomalies is diagonally oriented in the NW-SE direction. Evidently this could be of geophysical interest. This so-called PaldiskiPskov gravity and aeromagnetic anomaly zone is related to the location of deepseated geological faults (Sildvee \& Vaher 1995). It is interesting as well that strong negative anomalies prevail in the Gulf of Riga, most likely caused by the large Riga rapakivi granite massif (see, e.g., Puura \& Flodén 1999). The anomaly minimum is as low as $-66 \mathrm{mGal}$, located at the eastern edge of this rapakivi batholith.

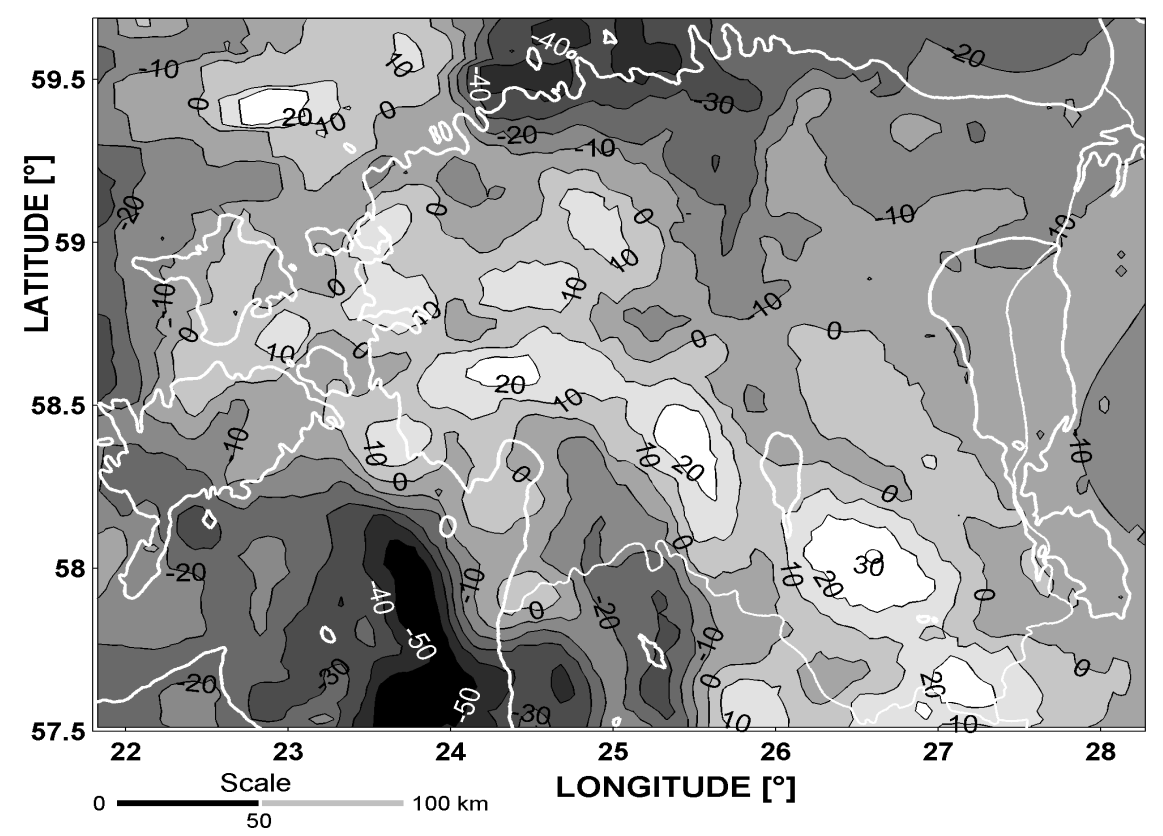

Fig. 3. The $1.5^{\prime} \times 3^{\prime}$ grid of free-air gravity anomalies in the target area. Units are in mGal; contour interval is $10 \mathrm{mGal}$. 


\section{COMPUTATION OF THE GEOID BY THE MODIFIED STOKES' FORMULA}

Published in 1849 by G. Stokes, the formula is the basis in physical geodesy. It enables the determination of the geoidal height $N$ from global coverage of the gravity anomalies:

$$
N=\frac{R}{4 \pi \gamma} \iint_{\sigma} S(\psi) \Delta g d \sigma
$$

where $R$ is the mean Earth's radius $(\sim 6371 \mathrm{~km}), \gamma$ is normal gravity, $\psi$ is geocentric angle, $S(\psi)$ is Stokes' function, and $d \sigma$ is a surface element of the unit sphere (Earth).

The double integral in Eq. (7) has to be evaluated over the whole Earth, which is an impractical requirement. Therefore, in practice, the area of integration is usually limited to a spherical cap around the computation point. The lack of a global coverage of gravity data can be compensated by a combination of terrestrial gravity with a GGM, i.e. the long-wavelength geoid contributions would be determined from a GGM and short-wavelength information from terrestrial gravity data.

Shown first by Molodensky et al. (1960), the truncation error of the remote zone can be reduced by introducing a modification of Stokes' formula. Assuming a cap of integration $\sigma_{0}$ with geocentric angle $\psi_{0}$ around the computation point, an estimator $\widetilde{N}$ of the geoidal height is provided by selected parameters $s_{0}, s_{1}, \ldots, s_{M}$ and gravity anomalies $\Delta \hat{g}$, inserted into the modified Stokes' formula

$$
\tilde{N}=\frac{R}{4 \pi \gamma} \iint_{\sigma_{0}} S_{M}(\psi) \Delta \hat{g} d \sigma+\frac{R}{2 \gamma} \sum_{n=2}^{M} s_{n} \Delta \hat{g}_{n},
$$

where the modified Stokes' function expressed in terms of Legendre polynomial $P_{k}$ is

$$
S_{M}(\psi)=S(\psi)-\sum_{k=0}^{M} \frac{2 k+1}{2} s_{k} P_{k}(\cos \psi) .
$$

Here it is assumed that the anomaly $\Delta g$ can be expanded into a series of Laplace harmonics:

$$
\Delta g=\sum_{n=2}^{\infty} \Delta g_{n}
$$

and the anomaly estimate, $\Delta \hat{g}_{n}$, could be calculated by Eq. (5). The upper modification limit $M$ is arbitrary and usually chosen by the upper degree of the available GGM.

When Molodensky (1960) introduced the idea of modification of Stokes' formula, the truncation error was the dominating error source. Some later alternatives from different authors (e.g. Wong \& Gore 1969) consider the truncation error as the only error source to be reduced. The above modification 
approaches were developed under the assumption that the errors stemming from the harmonic coefficients and measured gravity anomalies are negligible, an assumption which is obviously not true. With access to the up-to-date high-degree Earth geopotential models, the truncation error loses some of its significance, and the errors of the potential coefficients become more important in the modified Stokes' formula. In particular, the contribution to the error budget from the recent high-degree potential coefficient models is most significant. One should also consider the erroneous terrestrial gravity data within the truncation cap.

A modification method proposed by Sjöberg (1984) allows minimization of the truncation error, the influence of erroneous gravity data and geopotential coefficients in the least squares sense. In contrast to Molodensky's original method, the least squares modification of Stokes' formula takes any known or estimated, random or systematic error into account.

\section{THE ESTONIAN GEOID MODEL EST-01}

To determine the gravimetric geoid accurately it is necessary to involve gravity data outside the target area as well. From a theoretical point of view, it could be desirable to consider the terrestrial data from as large a cap as possible. However, we have the case where data around the target area are inhomogeneous. In particular, we lack data from the east of Estonia. From that point of view it is preferable to restrict the computations to the data whose nature is known and accuracy characteristics can be estimated. Though, as is demonstrated in Ellmann (2001), limiting the truncation cap to $1^{\circ}$ (approx. $110 \mathrm{~km}$ ) causes significant loss of accuracy. The Estonian gravimetric geoid is calculated by using the EGM96 as a reference model and the method of the least squares modification of Stokes' formula. The least squares modification coefficients, $s_{n}$, are calculated from the following initial conditions: (1) degree of modification $M=360$, (2) terrestrial anomaly variance $C(0)=9 \mathrm{mGal}^{2}$ (a correlation length of $0.1^{\circ}$ is assumed), (3) truncation cap radii $2^{\circ}$ (approx. $220 \mathrm{~km}$, the extremes are shown in Fig. 1 as a polygon).

Inserting into Eq. (8) the $1.5^{\prime} \times 3^{\prime}$ grid of free-air anomalies, least squares modification coefficients, and $\Delta \hat{g}_{n}$ from EGM96 resulted in the Estonian geoid model. This model is completed with necessary corrections which have to be introduced in the geoid determination process. Principles, applied formulas, and results of numerical studies are explicitly considered in Ellmann (2001). The new gravimetric geoid for Estonia is referred to as EST-01 and is presented in Fig. 4.

The geoidal heights are decreasing towards the northeast, whereas the extremes of 21 and $16 \mathrm{~m}$ are located the southwest and northeast corners, respectively (the length of this diagonal is $\sim 400 \mathrm{~km}$ ). The geoid is mainly smooth but includes local irregularities in the western and southern parts of the target area. It is interesting to notice that the geoid is locally depressed in the Gulf of Riga. The depression is obviously due to the negative, rapakivi-affected anomalies within this 


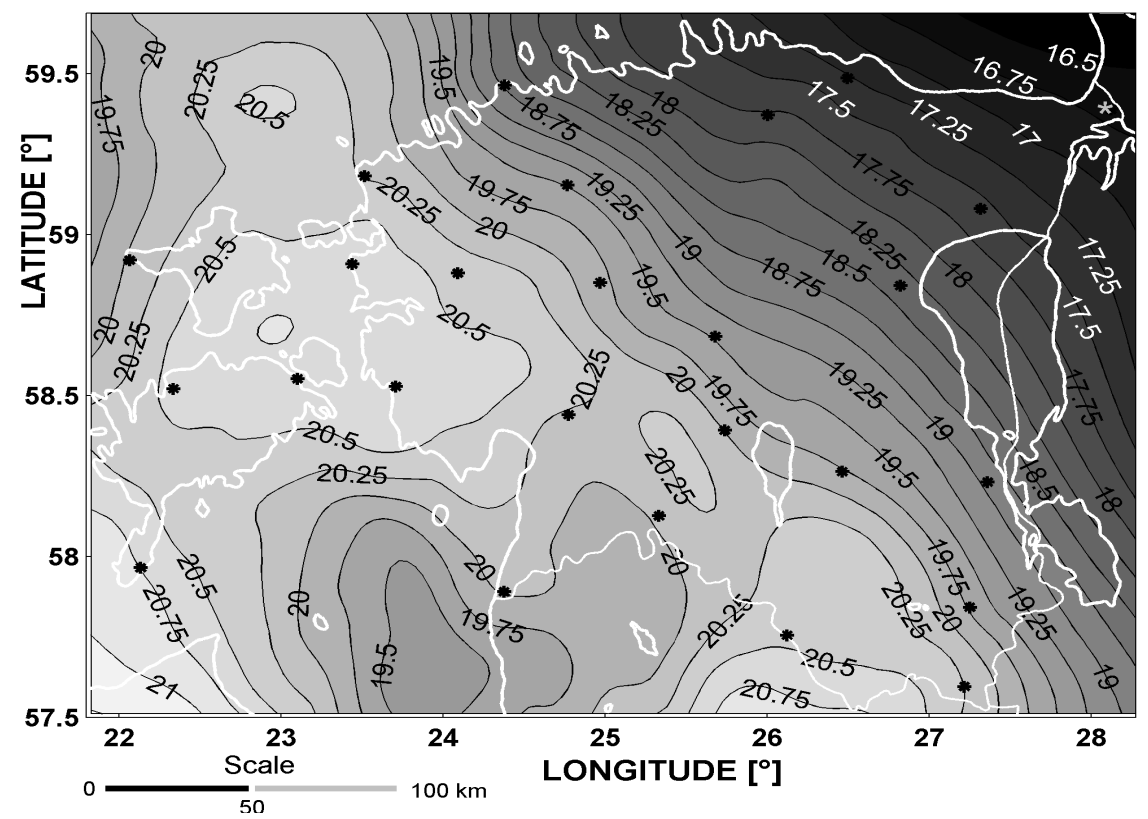

Fig. 4. The Estonian gravimetric geoid model EST-01. Computed from the least squares modification of Stokes' formula, degree of modification $M=360$, truncation cap $2^{\circ}$, anomaly variance $9 \mathrm{mGal}^{2}$. Geoidal heights are given with respect to the GRS-80. Units are metres and the contour interval is $0.25 \mathrm{~m}$. Black stars indicate the location of the GPS-levelling points.

area. Similar behaviour of the geoidal surface has been observed at the rapakivi batholiths in southern Finland (e.g. in the Wiborg area; Vermeer 1994).

Generally, the shape of the EST-01 geoid model is similar to the previous ones (Vermeer 1994; Forsberg et al. 1997). The detected discrepancies can partly be caused by the use of different computational methods, but obviously, the significantly improved gravity coverage has also been advantageous in this research. For example, in the Gulf of Riga area the local extreme of the EST-01 model has been shifted westwards compared to the model by Vermeer (1994). It is most likely caused by the improved dataset for this area.

A practical application of a geoid model is the transformation of heights. The inter-comparison of a geoid model, GPS-derived and spirit-levelled heights at discrete points gives a reasonable indication of the suitability of the gravimetric geoid model for this purpose. The EST-01 model is validated by 26 Estonian geodetic points (for their locations see Fig. 4). At these points the combined error of GPS-derived and spirit levelled heights cannot be greater than $2-3 \mathrm{~cm}$. The 26 points form the "geometric geoid model" which may be considered as the practical realization of the height system. As expected, the shapes of the 
geometric and gravimetric geoid models are almost the same, but the geometric geoid model is systematically lower than the gravimetric one. The mean bias of $-30 \mathrm{~cm}$ and a small SW-NE oriented tilt $(30 \mathrm{~cm}$ per $350 \mathrm{~km})$ between the models are detected. This may most likely indicate the influence from the EGM96 related long-wavelength effect.

National fit of the EST-01 model with the GPS-levelling points allows a wide spectrum of practical applications primarily associated with the use of the GPStechnology. The set of 26 GPS-levelling points was used for definition of the four transformation parameters between the two geoid models. A root mean square error of post-fitting residuals at GPS-levelling points on the level of $3 \mathrm{~cm}$ was achieved.

\section{DISCUSSION AND CONCLUSIONS}

A prediction of the gravity anomalies over Estonia was presented in this paper. The grid of free-air anomalies is utilized in the computations of the new gravimetric geoid for Estonia.

The study comprises significantly improved gravity data coverage in the Baltic Sea region in the last few years. Besides the Estonian data, the gravity anomalies from the neighbouring countries and offshore are involved as well. The quality of the data has been validated and any erroneous records have either been corrected or removed. However, some, mainly very small systematic biases between datasets originating from different countries may exist. Consequently, a careful and versatile revision of the gravity survey results of all Baltic Sea countries is desired. This can be done only within the frame of international cooperation, undoubtedly resulting in great rewards. First of all, the further unification of the Nordic-Baltic gravity data leads to the improvement of the anomaly grid and thus implies a more accurate geoid determination.

The regular $1.5^{\prime} \times 3^{\prime}$ grid of free-air anomalies over Estonia is predicted by using Bjerhammar's deterministic method. The estimated precision of the gravity anomaly grid is $2.4 \mathrm{mGal}$ in Estonia. Evidently, this precision can be improved. A separate study dedicated to the comparison of 1949-58 gravity survey results with other Estonian datasets (such as national gravity network, and detailed gravity survey of 1961-90 initiated mainly by the Geological Survey of Estonia) can be suggested. Depending on the results of such a comparison, the additional justification between those datasets may be necessary.

The anomalies computed from the EGM96 geopotential model have been used in order to improve the quantity and coverage in the eastern part of the target area. The lack of gravity data from large areas strongly affects the computational results. A noticeable improvement of the anomaly grid (and geoid model), especially in the eastern part of the target area, is expected after the missing data become available. 
We also conclude that in a lowland such as Estonia the free-air anomalies in a regular grid are most effectively predicted directly, compared to those predicted via Bouguer anomalies. The involvement of a precise and high-resolution national terrain model could improve the prediction results in the areas with rougher topography. On the other hand, the data from neighbouring countries are also involved. This puts additional requirements on data treatment and special procedures need to be adopted.

The EGM96 was used as a reference geopotential model in this study. As is well known, the appropriate reference geopotential model is essential to determine the gravimetric geoid accurately. Major expectations for the improved GGM are related to the already launched (or planned) satellite missions, devoted in particular to the studies of the Earth's gravitational field. The first decade of this century is expected to provide us with high-resolution and precise models of the Earth's gravitational field and new insight into its variations over time. This gives new perspectives for the development of methods leading to future geoid models accurate to $1 \mathrm{~cm}$.

The least squares modification of Stokes' formula has been applied to the computation of the new Estonian gravimetric geoid. In contrast to other modification methods, the least squares modification (Sjöberg 1984) takes any known or estimated random or systematic error into account. The set of used modification coefficients is calculated by the following initial conditions: modification degree 360 , terrestrial gravity anomaly variance $9 \mathrm{mGal}^{2}$, and truncation cap radius $2^{\circ}$. The anomaly grid and modification coefficients are utilized for the determination of the Estonian geoid model, referred to as EST-01.

The EST-01 is validated by fitting this to a set of 26 high-precision GPSlevelling points. An accuracy of $3.0 \mathrm{~cm}$ is achieved for post-fitting residuals, which indicates the suitability of the EST-01 geoid model for many practical applications. In particular, the combined use of GPS and EST-01 provides an alternative and cost-effective method to geodetic levelling and many scientific applications, such as geodetic positioning, geophysical and geological exploration.

\section{ACKNOWLEDGEMENTS}

The author is grateful to Prof. L. Sjöberg for a constructive review of an earlier version of the manuscript. The reviewers, Prof. M. Vermeer and Dr. J. Plado, are cordially acknowledged for useful comments and suggestions. Thanks go to Dr. G. Strykowsky, Danish National Survey and Cadastre, for providing gravity data and relevant information. This research was compiled within the frame of postgraduate studies in geodesy at the KTH, financially supported by the Kami Research Foundation. 


\section{REFERENCES}

Bjerhammar, A. 1973. Theory of Errors and Generalized Matrix Inverses. Elsevier, Amsterdam.

Ellmann, A. 2001. Least Squares Modification of Stokes Formula with Application to the Estonian Geoid. Licentiate Thesis in Geodesy, Geodesy Report No. 1056, Royal Institute of Technology (KTH), Stockholm.

Estonian Land Board. 1996. Estonian Base Map (Scale 1:50 000, digital).

Forsberg, R. 2001. Development of a Nordic cm-geoid with basics of geoid determination. In Nordic Geodesy Towards the 21st Century. Lecture Notes for Autumn School, Nordic Geodetic Commission (Harsson, B. G., ed.), pp. 67-88. Statens kartverk, Geod. Publ. 2001:1, Hønefoss, Norway.

Forsberg, R., Kaminskis, J. \& Solheim, D. 1997. Geoid of the Nordic and Baltic Region from gravimetry and satellite altimetry. In Gravity, Geoid and Marine Geodesy (Segawa, J., Fujimoto, H. \& Okubo, S., eds.). IAG Symp. Series, 117, 540-547.

GLOBE task team (Hastings, D. A., Dunbar, P. K., Elphingstone, G. M., Bootz, M., Murakami, H., Maruyama, H., Masaharu, H., Holland, P., Payne, J., Bryant, N. A., Logan, T. L., Muller, J.-P., Schreier, G. \& MacDonald, J. S., eds.). 1999. The Global Land One-kilometer Base Elevation (GLOBE) Digital Elevation Model, Version 1.0. National Oceanic and Atmospheric Administration, National Geophysical Data Center.

Heiskanen, W. A. \& Moritz, H. 1967. Physical Geodesy. Freeman, San Fransisco.

Jürgenson, H. 1999. Gravity measurements and calculations of the geoid model for Estonia. Estonian Agricultural University, Tartu (unpubl.).

Kaminskis, J. \& Forsberg, R. 1997. A new detailed geoid for Latvia. In Gravity, Geoid and Marine Geodesy (Segawa, J., Fujimoto, H. \& Okubo, S., eds.), IAG Symp. Series, 117, 621-628.

Lemoine, F. G., Smith, D. E., Kunz, L., Smith, R., Pavlis, E. C., Pavlis, N. K., Klosko, S. M., Chinn, D. S., Torrence, M. H., Williamson, R. G., Cox, C. M., Rachlin, K. E., Wang, Y. M, Kenyon, S. C., Salman, R., Trimmer, R., Rapp, R. H. \& Nerem, R. S. 1997. The development of the NASA GSFC and NIMA Joint Geopotential Model. In Gravity, Geoid and Marine Geodesy (Segawa, J., Fujimoto, H. \& Okubo, S., eds.), IAG Symp. Series, 117, 461-469.

Molodensky, M. S. 1945. The principal problems of geodetic gravimetry. Trudy TsNIIGAiK, 42, Geodezizdat, Moscow (in Russian).

Molodensky, M. S., Eremeev, V. F. \& Yurkina, M. I. 1960. Methods for study of the external gravitational field and figure of the Earth. Trudy TsNIIGAiK, 131, Moscow (in Russian).

Moritz, H. 1992. Geodetic reference system 1980. Bull. Geod., 66, 187-192.

Puura, V. \& Flodén, T. 1999. Rapakivi-granite-anorthosite magmatism - a way of thinning and stabilisation of the Svecofennian crust, Baltic Sea Basin. Tectonophysics, 305, 75-92.

Sildvee, H. 1998. Gravity Measurements of Estonia. Rep. of the Finnish Geod. Inst., 98:3, Masala.

Sildvee, H. \& Oja, T. 2000. Aastatel 1970-2000 Eestis mõõdetud gravimeetriliste võrkude andmebaas. Tehniline aruanne. Technical report. Estonian National Land Board Development Centre, Tallinn.

Sildvee, H. \& Vaher, R. 1995. Geologic structure and seismicity of Estonia. Proc. Estonian Acad. Sci. Geol., 44, 15-25.

Sjöberg, L. E. 1984. Least Squares Modification of Stokes and Vening-Meinesz Formulas by Accounting for Errors of Truncation, Potential Coefficients and Gravity Data. The Department of Geodesy Report No. 27, University of Uppsala, Uppsala.

Sjöberg, L. E. 1999. The IAG approach to the atmospheric geoid correction in Stokes formula and a new strategy. J. Geod., 73, 362-366.

Wong, L. \& Gore, R. 1969. Accuracy of geoid heights from the modified Stokes kernels. Geophys. J. Roy. Astron. Soc., 18, 81-91.

Vermeer, M. 1994. A Fast Delivery GPS-gravimetric Geoid for Estonia. Rep. of Finnish Geod. Inst., 94:1, Helsinki. 


\title{
Täpsustatud raskusjõu anomaaliate võrgustik ja geoidi mudel Eestis
}

\begin{abstract}
Artu Ellmann
Interpoleerimise meetodil on moodustatud kogu Eestit kattev raskusjõu vabaõhu anomaaliate $1.5^{\prime} \times 3^{\prime}$ võrgustik. Arvutustesse on kaasatud viimastel aastatel Läänemere regioonis lisandunud gravimeetrilised andmed. Moodustatud võrgu hinnanguline täpsus on 2,4 mGal. Seejärel on vabaõhu anomaaliate võrku ning geopotentsiaali mudelit EGM96 kasutatud Eesti gravimeetrilise geoidi kuju määramiseks. Geoidi arvutustöödes on rakendatud vähimruutude meetodil modifitseeritud Stokesi valemit. Eesti geoidi mudeli EST-01 täpsushinnanguks ning kõrgussüsteemiga ühildamiseks kasutati 26 kõrgtäpset GPS-nivelleerimise punkti. Jääkerinevuste põhjal on arvutatud ühildamise täpsus $3,0 \mathrm{~cm}$, mis võimaldab EST-01 mudelit rakendada paljude praktiliste ülesannete lahendamisel.
\end{abstract}

\section{Улучшенные сеть аномалий силы тяжести и модель геоида для территории Эстонии}

\begin{abstract}
Арту Эллманн
Регулярная сеть $1,5^{\prime} \times 3^{\prime}$ аномалий силы тяжести для территории Эстонии получена путем интерполирования. В работе использованы также достижения последних лет по охвату гравиметрическими данными региона Балтийского моря. Установленная точность сети аномалий в пределах Эстонии составила 2,4 мгал. Полученная сеть и геопотенциальная модель EGM96 использованы для определения гравиметрического геоида. При вычислениях применялась модифицированная с помощью метода наименьших квадратов формула Стокса. Модель геоида EST-01 совмещена с 26 высокоточными пунктами GPS-нивелирования. Достигнутая точность совмещения - 3 см - позволяет применять модель EST-01 при решении многих прикладных задач.
\end{abstract}

